\title{
Different capabilities of monocytes from patients with systemic lupus erythematosus and rheumatoid arthritis to induce glycosylation alterations of acute phase proteins in vitro
}

Andrzej Mackiewicz, Magdalena Sobieska, Małgorzata Kapciñska, Stefan H Mackiewicz, Krzysztof E Wiktorowicz, Tomasz PawYowski

\begin{abstract}
The effect of conditioned medium on the biosynthesis and glycosylation profile of acute phase proteins secreted by the human hepatoma cell line Hep G2 was studied. Conditioned medium was prepared from nonactivated [CM-LPS $(-)$ ] and ex vivo lipopolysaccharide activated [CM-LPS $(+)$ ] monocytes from eight patients with active rheumatoid arthritis (RA), five patients with active systemic lupus erythematosus (SLE), and seven healthy subjects. The biosynthesis of albumin, $\alpha_{1}$-antichymotrypsin and $\alpha_{1-}$ proteinase inhibitor and the profile of glycosylation of proteinase inhibitor were analysed. CM-LPS(-) from patients with SLE had a similar effect to CM-LPS(-) from healthy subjects. In contrast, CM-LPS(-) from patients with $R A$ had the same effect as CM-LPS $(+)$ from healthy donors. A similar effect to that of CM-LPS $(+)$ of healthy subjects was seen with CM-LPS(+) from patients with SLE and with CM-LPS( + ) from patients with RA. The treatment of CM-LPS $(+)$ with antibodies against interleukin 6 neutralised most of its ability to induce changes in the biosynthesis and glycosylation of acute phase proteins. Antibodies to interleukin 1 and tumour necrosis factor $\alpha$ had only a limited effect on the ability of CM-LPS(+) to induce changes of albumin and $\alpha_{1-}$ antichymotrypsin syntheses, whereas they had no effect on the biosynthsis and glycosylation of proteinase inhibitor. These results indicate that: $(a)$ monocytes isolated from patients with active SLE and active RA have different capabilities of inducing alterations of acute phase proteins in vitro; (b) ex vivo activation of monocytes from patients with SLE leads to the full induction of its capabilities to change acute phase proteins, whereas the activation of monocytes from patients with RA has no additive effect; and (c) interleukin 6 seems to be a major cytokine involved in the regulation of the glycosylation pattern of acute phase proteins.
\end{abstract}

Following tissue injury, infection, or various inflammatory processes, a number of normal homeostatic mechanisms are substantially changed. ${ }^{1}$ The characteristic pattern of these alterations is termed the acute phase response and includes changes in the concentration of a number of plasma proteins referred to as acute phase proteins. ${ }^{1}{ }^{2}$ Quantitative changes in acute phase proteins are often accompanied by qualitative alterations of their carbohydrate moieties; this is referred to as microheterogeneity. Two types of microheterogeneity have been distinguished $^{3}$ : major microheterogeneity, which reflects changes in the number of branches on heteroglycan antennary structures; and minor microheterogeneity which includes variations in the sialic acid or fucose content. Affinity electrophoresis with concanvalin A as a ligand has been widely used for the determination of major microheterogeneity of acute phase proteins in serum samples. ${ }^{4-10}$ In this system microheterogeneous forms with biantennary heteroglycans can be separated from forms having tri- and/or tetra-antennary units. ${ }^{11}$ For multiheteroglycan proteins the degree of reactivity with concanavalin A depends on the number of biantennary structures present on the molecule. ${ }^{11}$

Two different types of changes in the glycosylation pattern of acute phase proteins in serum samples were found; type I, characterised by an increase in the relative amount of biantennary over more branched structures (increased concanavalin A reactivity), which is seen in patients with acute inflammatory processes; and type II, with a decrease in the relative amount of biantennary over more branched units (decreased concanavalin A reactivity), which is found in patients with chronic inflammatory disease. ${ }^{10}$

A decrease in reactivity with concanavalin A of a number of acute phase proteins, mostly marked for $\alpha_{1}$ acid glycoprotein, which was parallel to the increase of disease activity has been seen in serum samples from patients with RA. ${ }^{8}$ However, in serum samples from patients with systemic lupus erythematosus (SLE), the reactivity of $\alpha_{1}$ acid glycoprotein with concanavalin A was similar to that seen in serum samples from healthy subjects. ${ }^{7}$ Serum samples from patients with RA and SLE who had intercurrent infections showed a dramatic increase of reactivity between concanavalin A and $\alpha_{1}$ acid glycoprotein. ${ }^{79}$

An in vitro system has been developed to study the mechanisms controlling the glycosylation changes of acute phase proteins. ${ }^{12-15} \mathrm{With}$ this system we have shown that alterations in the glycosylation of acute phase proteins observed in serum samples result from changes occurring within hepatocytes and are mediated by cytokines such as interleukin 6 , transforming growth factor $\beta 1$, and, to some extent, tumour 
necrosis factor $\alpha$. Moreover, the activity of interleukin 6 and transforming growth factor $\beta$ may be modulated by interleukin 1 and tumour necrosis factor $\alpha$. We have also found that the mechanisms regulating the glycosylation changes of acute phase proteins are independent of mechanisms regulating the gene expression of these proteins.

The monocyte/macrophage plays a central part in the mediation of acute phase response events. Cytokines released by this cell are involved in the regulation of gene expression and alterations of the glycosylation of the acute phase proteins in the liver. ${ }^{14-19}$ These studies were performed to appraise the capabilities of monocytes isolated from patients with active SLE and RA to affect the glycosylation profile of acute phase proteins in vitro. We evaluated both the spontaneous abilities and the abilities of ex vivo activated monocytes. To characterise the cytokines involved in these processes, we neutralised the inducing activity of cytokines secreted by monocytes using specific antibodies.

\section{Patients and methods \\ PATIENTS}

Heparinised blood was obtained from five patients with active SLE (grade III of activity), eight patients with active RA (grade IV of activity) and seven healthy subjects. SLE and classic RA were diagnosed based on the American Rheumatism Association criteria. ${ }^{20} 21$ The activity of SLE was assessed according to the Rothfield and Pace scale, ${ }^{22}$ whereas the activity of RA was assessed according to Mallya and Mace. ${ }^{23}$

\section{PREPARATION OF CONDITIONED MEDIUM FROM ACTIVATED AND NON-ACTIVATED HUMAN PERIPHERAL BLOOD MONOCYTES}

Mononuclear cells were isolated from $50 \mathrm{ml}$ of heparinised peripheral blood collected from patients with SLE, RA, and healthy subjects, using Ficoll-uropolinum gradient centrifugation. The cell population obtained was suspended in Eagle's minimal essential medium (Biomed, Poland $\left(3 \times 10^{6}\right.$ cells $\left./ \mathrm{ml}\right)$ and supplemented with $20 \%$ fetal calf serum (Gibco Laboratories) and antibiotics. A $10 \mathrm{ml}$ volume of the prepared suspension was placed into plastic Petri dishes $(100 \mathrm{~mm})$ and the cells were incubated for one and a half hours. Adherent cells, $80-90 \%$ of which were positive for non-specific esterase staining, ${ }^{24}$ were washed and incubated for a further 24 hours in $5 \mathrm{ml}$ of serum free Eagle's minimal essential medium containing antibiotics. This medium was referred to as CM-LPS(-). For the preparation of CM-LPS(t), $20 \mu \mathrm{g} / \mathrm{ml}$ of lipopolysaccharide from Escherichia coli 055:B5 (Sigma Chemical) was added to the medium.

\section{NEUTRALISATION OF THE ACTIVITY OF} CONDITIONED MEDIUM WITH ANTIBODIES DIRECTED AGAINST SPECIFIC CYTOKINES

In two independent experiments, CM-LPS(+) prepared from monocytes isolated from two different healthy subjects was incubated with specific polyclonal antibodies directed against cytokines. Antibodies to interleukin 6 (a gift of Dr P Seghal, Rockefeller University, New York, NY, USA), interleukin $1 \alpha$ (Genzyme, Boston, MA, USA), interleukin $1 \beta$ (a gift of Dr C A Dinarello, Tufts University Medical School, Boston, MA, USA), tumour necrosis factor $\alpha$ (a gift of $\mathrm{Dr} J$ Mathison, Scripps Clinic Foundation La Jolla, CA, USA) were added separately and together to CM-LPS $(+)$ and incubated for two hours at $37^{\circ} \mathrm{C}$. The amounts of antibodies used were based on titration results. The minimum amount of each antibody generating the maximum neutralisation of conditioned medium to inhibit albumin synthesis was selected. As a control, preimmune rabbit serum was incubated with CM-LPS $(+)$ in corresponding volumes.

INDUCTION OF CHANGES IN ACUTE PHASE PROTEINS IN THE HUMAN HEPATOMA CELL LINE HEP G2

After subculture, cells were maintained in plastic Petri dishes ( $35 \mathrm{~mm}$ ) in Eagle's minimal essential medium with $10 \%$ fetal calf serum for five days and then for 24 hours in serum free minimal essential medium supplemented with dexamethasone $(1 \mu \mathrm{mol} / \mathrm{l})$ and insulin $(0.02 \mathrm{U} / \mathrm{ml})$. The Hep G2 cells were then exposed to a $10 \%$ solution of CM-LPS $(-)$ and CM-LPS (+) obtained from healthy subjects and patients with SLE and RA, in addition to $20 \%$ CMLPS(+) from healthy subjects treated with antibodies against cytokines. In control cultures cells were exposed to minimal essential medium alone. The cells were then incubated for an additional 72 hours with the replacement of medium (containing conditioned medium) every 24 hours. Analyses were carried out in media collected during the final 24 hours. Each experiment was run in duplicate or triplicate.

\section{QUANTITATION OF ACUTE PHASE PROTEINS}

ACCUMULATED IN COLLECTED CULTURE MEDIA

Concentrations of albumin, $\alpha_{1}$-antichymotryp$\sin$, and $\alpha_{1}$-protease inhibitor secreted into the culture media by Hep G2 cells were determined by quantitative electroimmunoassay ${ }^{25}$ with monospecific antibodies, using a human serum calibrator kit (Atlantic Antibodies) as a standard. The results were expressed as a percentage increase or decrease over control experiments. We have previously shown ${ }^{21}$ that the increased accumulation of proteinase inhibitor in Hep 3B cell medium was parallel to the increase of newly synthesised ${ }^{35} \mathrm{~S}$-methionine labelled proteinase inhibitor and the increase in its intracellular mRNA concentration. Thus, the changed accumulation of proteins in the medium reflects, in general, changes in the rate of their synthesis by the hepatoma cell lines.

DETERMINATION OF PROTEINASE INHIBITOR MICROHETEROGENEITY

Patterns of proteinase inhibitor glycosylation were studied by agarose affinity electro- 
phoresis with concanavalin A $(50 \mu \mathrm{mol} / \mathrm{l}$; Sigma Chemical). ${ }^{26}$ The area under the precipitate curves was determined by planimetry and the relative amounts of the different microheterogeneous forms were expressed as percentages of the total. A reactivity coefficient for each sample was calculated according to the relation: sum of concanavalin A reactive variants/ concanavalin A non-reactive variant.

All statistical analyses were carried out by the Mann-Whitney test.

\section{Results}

EFFECT OF CONDITIONED MEDIUM ON SYNTHESIS OF ALBUMIN, $\alpha_{1}$-ANTICHYMOTRYPSIN AND PROTEINASE INHIBITOR BY THE HEP G2 CELL LINE Table 1 shows changes in the synthesis of the studied proteins by Hep G2 cells exposed to various conditioned medium preparations. CM-LPS(-) and CM-LPS(+) obtained from healthy subjects reduced the synthesis of albumin to the same degree. Similarly, there was no significant difference between the effect on albumin production of CM-LPS(-) and CM-LPS $(+)$ obtained from patients with RA and SLE. The total reduction of albumin synthesis by conditioned medium from patients with RA was more pronounced, whereas the reduction by conditioned medium from patients with SLE was less pronounced than the reduction caused by conditioned medium from healthy subjects. CM-LPS(+) obtained from healthy subjects or patients with SLE had stronger effects than the corresponding CM-LPS(-) on the increase of $\alpha_{1}$-antichymotrypsin and proteinase inhibitor synthesis. In contrast, CM-LPS(-) from patients with RA increased the synthesis of $\alpha_{1}$ antichymotrypsin and pro-

Table 1 Albumin (Alb), $\alpha_{1}$-antichymotrypsin (ACT), and $\alpha_{1}$-proteinase inhibitor (PI) synthesised by Hep G2 cells exposed to conditioned medium obtained from healthy subjects and patients with rheumatoid arthritis and systemic lupus erythematosus. Control value was 100 in all instances; results expressed as mean $(S D)$ percentage of control

\begin{tabular}{llll}
\hline Subjects & Protein & $C M-L P S(-)$ & $C M-L P S(+)$ \\
\hline Healthy subjects (n=7) & Alb & $40(5)^{*}$ & $41(10)^{*}$ \\
& ACT & $555(35)^{*}$ & $880(50)^{*} \dagger$ \\
& PI & $140(10)^{*}$ & $210(25)^{*} \dagger$ \\
Patients with RA (n=8) & Alb & $35(5)^{*}$ & $38(5)^{*}$ \\
& ACT & $910(35)^{*}$ & $940(35)^{*}$ \\
& PI & $205(25)^{*}$ & $230(20)^{*}$ \\
Patients with SLE (n=5) & Alb & $54(2)^{*}$ & $50(3)^{*}$ \\
& ACT & $670(30)^{*}$ & $800(20)^{*}+$ \\
& PI & $110(15)$ & $190(20)^{*} \dagger$ \\
\hline
\end{tabular}

"Significant difference compared with control. †Significant difference compared with CM-LPS(-). teinase inhibitor to the same high degree as CM-LPS(+).

\section{EFFECT OF CONDITIONED MEDIUM ON THE}

MICROHETEROGENEITY OF PROTEINASE

INHIBITOR SYNTHESISED BY THE HEP G2 CELL

LINE

Affinity electrophoresis with concanavalin A as a ligand revealed three microheterogeneous forms of proteinase inhibitor (fig): variant 0 , not reactive with concanavalin $A$; variant 1 , weakly reactive with concanavalin $A$; and variant 2 , reactive with concanavalin $A$. The figure shows the changes in the proteinase inhibitor glycosylation pattern caused by various conditioned medium preparations. Table 2 gives the reactivity of concanavalin $A$ with proteinase inhibitor expressed as a reactivity coefficient. All conditioned medium preparations affected the reactivity of proteinase inhibitor with concanavalin A compared with controls. CM-LPS(+)obtained from healthy subjects and patients with SLE had a stronger effect on the reactivity of proteinase inhibitor with concanavalin $A$ than CM-LPS(-) prepared from the same cells. The degree of alteration caused by CM-LPS(-) from patients with SLE was the same as that caused by the corresponding conditioned medium from healthy subjects. In contrast, CM-LPS(-) obtained from patients with RA affected the reactivity of proteinase inhibitor with concanavalin $A$ to the same degree as CM-LPS(+), which was similar to that of CM-LPS $(+)$ from patients with SLE and healthy subjects. The inducing capabilities for the synthesis and glycosylation of acute phase proteins of non-activated monocytes from healthy subjects [CM-LPS $(-)$ ], which served here as controls, may be due to the partial activation of these cells by adherence to the plastic and/or to possible endotoxin contamination in the laboratory. ${ }^{27}$

Table 2 Reactivity of concanavalin A with proteinase inhibitor secreted by Hep $G 2$ cells exposed to conditioned medium obtained from healthy subjects, and patients with rheumatoid arthritis and systemic lupus erythematosus. Control value $4 \cdot 0(0 \cdot 3)$ in all instances; reactivity coefficient is sum of reactive variants/non-reactive variants (mean $(S D)$ )

\begin{tabular}{llll}
\hline Subjects & $n$ & $C M-L P S(-)$ & $C M-L P S(+)$ \\
\hline Healthy subjects & 7 & $2 \cdot 0(0 \cdot 2)^{*}$ & $1 \cdot 0(0 \cdot 3)^{*} \dagger$ \\
Patients with RA & 8 & $1 \cdot 2(0 \cdot 2)^{*} \dagger$ & $1 \cdot 0(0 \cdot 1)^{*} \dagger$ \\
Patients with SLE & 5 & $2 \cdot 1(0 \cdot 2)^{*}$ & $1 \cdot 2(0 \cdot 1)^{*} \dagger$ \\
\hline
\end{tabular}

"p<0.001 compared with control.

tP<0.001 compared with CM-LPS(-) of healthy subjects.
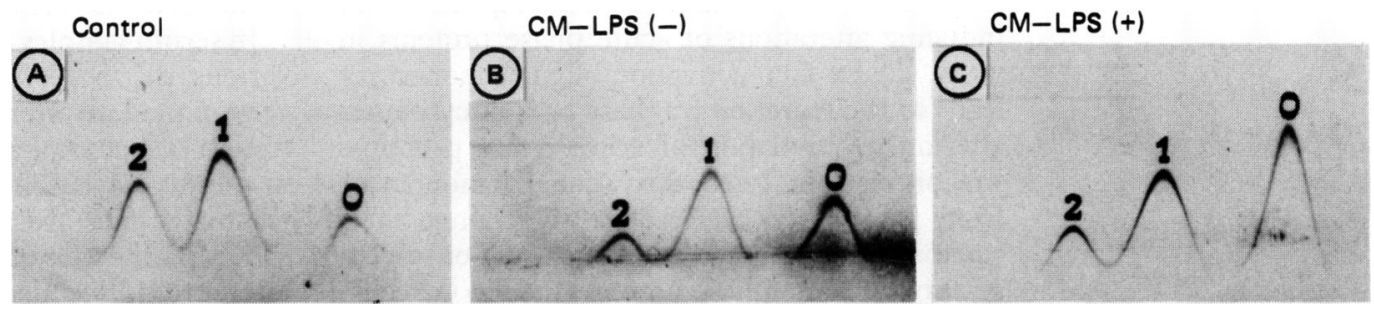

Affinity electrophoresis with concanavalin $A$ of proteinase inhibitor synthesised by the Hep G2 cell line. (A) Control experiment, $(B)$ incubation with $C M-L P S(-)$ from a healthy subject, end $(C)$ incubation with $C M-L P S(+)$ from a healthy subject. 
Table 3 Effect of specific antibodies to interleukin $6,1 \alpha, 1 \beta$, and tumour necrosis factor $\alpha$ on induction of biosynthesis of acute phase proteins and glycosylation by conditioned medium in Hep G2 cells. Abbreviations as in table 1

\begin{tabular}{|c|c|c|c|c|}
\hline & $A l b$ & $A C T$ & $P I$ & $P I-R C$ \\
\hline $\begin{array}{l}\text { Control subject* } \\
\text { Preimmune serum } \\
\text { Conditioned medium }(20 \%) \\
\text { Conditioned medium }+ \text { preimmune serum } \\
\text { Conditioned medium }+ \text { interleukin } 6 \text { antibody } \\
\text { Conditioned medium + tumour necrosis factor } \alpha \text { antibody } \\
\text { Conditioned medium + interleukin } 1 \alpha \text { and } 1 \beta \text { antibodies } \\
\text { Conditioned medium + interleukin } 6+1 \alpha+1 \beta+\text { tumour }\end{array}$ & $\begin{array}{l}100 \\
98(3) \\
27(5) \\
26(6) \\
45(7) \\
60(10) \\
50(5)\end{array}$ & $\begin{array}{l}100 \\
99(12) \\
990(120) \\
980(110) \\
300(40) \\
820(60) \\
860(60)\end{array}$ & $\begin{array}{l}100 \\
99(8) \\
250(10) \\
255(15) \\
130(20) \\
250(15) \\
250(10)\end{array}$ & $\begin{array}{l}4 \cdot 0(0 \cdot 2) \dagger \\
4 \cdot 1(0 \cdot 2) \\
1 \cdot 0(0 \cdot 1) \\
1 \cdot 1(0 \cdot 1) \\
3 \cdot 0(0 \cdot 2) \\
1 \cdot 3(0 \cdot 1) \\
1 \cdot 0(0 \cdot 1)\end{array}$ \\
\hline necrosis factor $\alpha$ antibodies & $80(15)$ & $200(30)$ & $130(20)$ & $3 \cdot 2(0 \cdot 2)$ \\
\hline
\end{tabular}

${ }^{*}$ Results expressed as (mean (SD) percentages of control value.

$\dagger$ Proteinase inhibitor-concanavalin A reactivity expressed as reactivity coefficient.

EFFECT OF CONDITIONED MEDIUM NEUTRALISED BY ANTIBODIES ON THE SYNTHESIS AND

GLYCOSYLATION OF THE STUDIED PROTEINS

Table 3 summarises the results obtained. Incubation of conditioned medium with antibodies to interleukin 6 , interleukin 1 , or tumour necrosis factor $\alpha$ caused partial neutralisation of its ability to inhibit albumin synthesis. The neutralising capabilities of all the antibodies were similar. The combination of all antibodies had an additive effect, but did not completely abolish the ability of the conditioned medium to inhibit albumin synthesis. All three antibodies had an inhibitory effect on the ability of the conditioned medium to increase $\alpha_{1}$ antichymotrypsin synthesis. Antibodies to interleukin 6 had the most pronounced neutralising activity, whereas the effects of antibodies to interleukin $1 \alpha$ and $1 \beta$ and tumour necrosis factor $\alpha$ were marginal. The combination of these three antibodies had an additive effect, but did not completely neutralise the ability of the conditioned medium to increase $\alpha_{1}$ antichymotrypsin synthesis. Only the antibody to interleukin 6 was able partially to inhibit the effect of the conditioned medium on proteinase inhibitor synthesis and its reactivity with concanavalin $A$. Antibodies to interleukin $1 \alpha$ and $\beta$ used separately or in combination with antibodies to interleukin 6 had an effect on proteinase inhibitor production and reactivity to concanavalin A. Antibodies to tumour necrosis factor $\alpha$ did not neutralise the capabilities of the conditioned medium to induce proteinase inhibitor synthesis. It is possible that antibodies to tumour necrosis factor $\alpha$ had a slight effect on the reactivity between proteinase inhibitor and concanavalin $\mathrm{A}$; however, more data are required to confirm this observation.

\section{Discussion}

There are three major findings of these studies. (a) Monocytes isolated from patients with active SLE and active RA have different capabilities of inducing alterations of acute phase proteins in vitro. (b) Ex vivo activation of SLE monocytes leads to the secretion by these cells of cytokines altering glycosylation of acute phase proteins. In contrast, in vitro activation of monocytes from patients with RA does not change their capabilities of inducing alterations of glycosylation in acute phase proteins in Hep G2 cells. (c) Interleukin 6 seems to be a major cytokine secreted by monocytes involved in the regulation of the glycosylation pattern of acute phase proteins. These studies have also shown (by indirect measures) that during active SLE there is an impaired spontaneous generation of interleukin 6 , interleukin 1 , and tumour necrosis factor $\alpha$ by peripheral blood monocytes, and during active RA this activity is enhanced.

We have shown ${ }^{13} 14$ in vitro that two different human hepatoma cells lines, Hep 3B and Hep G2, show various patterns of alterations of the glycosylation of acute phase proteins on induction with a crude cytokine preparation. The alterations resemble those seen in serum samples from patients with SLE and RA. Using these two lines as a model, we have shown that a number of cytokines in various specific combinations may affect the pattern of glycosylation of proteinase inhibitor, a model positive acute phase protein. Interleukin 6 seems to induce two types of alterations, type I which is seen in patients with acute inflammatory processes and type II which is found in serum samples from patients with chronic inflammatory disease. Transforming growth factor $\beta$ induces only type I alterations, whereas tumour necrosis factor $\alpha$ has only a slight effect on type II changes. Interleukin 1 used alone has no effect on any of the alterations. However, when interleukin 1 was added to interleukin 6, it increased its effect on type I but not on type II changes. In contrast, tumour necrosis factor $\alpha$ added to interleukin 6 potentiated its effect on type II, but not on type I alterations. The addition of either interleukin 1 or tumour necrosis factor $\alpha$ to transforming growth factor $\beta$ inhibited the capabilities for inducing type I alterations. The combination of interleukin 6 with transforming growth factor $\beta$ had an additive effect on inducing type I and the opposite effect on inducing type II glycosylation changes. These data, taken together with the results of changes in the biosynthesis of acute phase proteins by cytokines, strongly suggest that specific subsets of cytokines are responsible for mediating type I and type II alterations in the glycosylation of acute phase proteins in addition to the biosynthesis of these proteins.

In serum samples from patients with SLE with various degrees of disease activity, there are very limited or often no changes in the concentration of acute phase proteins. ${ }^{72}$ Alterations in the glycosylation of acute phase proteins in serum samples are not found ${ }^{7}$ in patients with active SLE, whereas patients with SLE with intercurrent infections have a significant increase in the number of acute phase proteins. ${ }^{28}$ Changes in the glycosylation of acute phase proteins (type I) are almost always found in these 
patients. In contrast, in the course of RA, the whole spectrum of (type II) alterations of acute phase proteins is seen, and the observed changes correlate with the degree of disease activity. ${ }^{89}$ Intercurrent infections do not have an additive effect on the concentration of acute phase proteins in serum, but have an opposite effect on the alterations (type I) in the glycosylation of acute phase proteins to that which the exacerbation of the disease evokes. ${ }^{9}$

These results indicate that differences in the pattern of glycosylation of acute phase proteins observed in patients with active SLE and active RA may be associated with different secretions of the cytokines involved in these processes. This finding suggests that activity of RA, but not SLE, is connected with activation of monocytes. Moreover, ex vivo activation by lipopolysaccharides of monocytes from patients with SLE corrected their impaired abilities to induce glycosylation alterations of acute phase proteins, indicating that these cells are capable of responding to exogenous inflammatory stimuli. This observation could explain the basis of altered glycosylation of acute phase proteins seen in patients with SLE with intercurrent infections; studies of monocytes isolated from such patients would directly support this hypothesis.

Monocytes secrete a number of cytokines known to be involved in mediating acute phase protein changes. These include interleukin 6 , interleukin $1 \alpha$ and $\beta$, tumour necrosis factor $\alpha$, and transforming growth factor $\beta$. The monocyte is not, however, the only cell which secretes cytokines mediating these events. Many other cell types can serve as sources of these cytokines, namely platelets, which are source of transforming growth factor $\beta,{ }^{29}$ or fibroblasts which secrete interleukin $6 .^{30} \mathrm{How}$ ever, fibroblasts, for instance, require interleukin 1 or tumour necrosis factor $\alpha$ for the induction of interleukin 6 production..$^{30}$ Thus, there is a link between the functional capabilities of monocytes and the activation of other cells, indicating that the defective function of monocytes in paients with SLE may lead to the impaired function of other cells involved in the acute phase response. Accordingly, for a final evaluation, the measurement of various cytokines in serum samples from patients with SLE would be useful. Houssiau et al reported ${ }^{31}$ raised levels of interleukin 6 in serum samples from patients with RA, which correlated with the increased concentrations of a number of acute phase proteins in serum. Fong et al ${ }^{32}$ observed the same phenomenon in serum samples from patients with endotoxaemia.

In these studies using antibodies against various cytokines, we were not able completely to neutralise the effect of conditioned medium on the induction of changes in the glycosylation of acute phase proteins. It is possible that other cytokines secreted either by monocytes or other adherent cells, which might be present in monocyte preparations, are involved in these processes. At the time of these studies, no neutralising antibodies against transforming growth factor $\beta$ were commercially available. However, the effect of transforming growth factor $\beta$ in Hep G2 cells is opposite to the effect of interleukin $6,{ }^{14}$ thus the neutralisation of transforming growth factor $\beta$ should lead to the increased effect of interleukin 6. In fact, the human hepatoma cell lines Hep G2 and Hep 3B should be used to gain a better understanding of the effect of conditioned medium on various types of glycosylation changes. However, owing to the limited number of cells obtained from patients, especially patients with SLE, the application of both lines in these studies was impossible.

The so called defective function of monocytes from patients with SLE has been reported, including reduced phagocytic activity, decreased hexose monophosphate shunt and glycolytic activity, and the defective production of interleukin $1 .{ }^{33}$ In contrast, the increased generation of interleukin 1 by monocytes from patients with active RA was found. ${ }^{35}$ Franchimont $e t$ al have shown ${ }^{36}$ that peripheral blood mononuclear cells from patients with RA did not spontaneously release tumour necrosis factor $\alpha$. In our studies we confirmed (by indirect measurements) earlier results of impaired and enhanced generation of interleukin 1 by monocytes from patients with SLE and RA, respectively, and explored the similar effects for interleukin 6 and tumour necrosis factor $\alpha$.

1 Kushner I, Mackiewicz A. Acute phase proteins as disease markers. Dis Markers 1987; 5: 1-11.

2 Koj A. Definition and classification of acute phase proteins. In: Gordon A H, Koj A, eds. The acute phase response to injury and infection. New York: Elsevier, 1985: 139-44.

3 Hatton M W C, Marz L, Regoeczi E. On the significance of heterogeneity of plasma glycoproteins possessing $\mathrm{N}$-glycans of the complex type: a perspective. Trends Biochem $\mathrm{Sci}$ 1983; 92: 287-91.

4 Nicollet I, Lebreton J P, Fontaine M, Hiron M. Evidence for alpha-1-acid glycoprotein populations of different $\mathrm{pI}$ values after Concanavalin A affinity chromatography: study of their evolution during inflammation in man. Biochim Biophys Acta 1981; 668: 235-45.

5 Raynes J. Variations in the relative proportions of microheterogeneous forms of plasma glycoproteins in pregnancy and disease. Biomedicine 1982; 36: 77-86.

6 Hansen J E, Jensen S P, Nørgaard-Pedersen B, Bøg-Hansen T C. Electrophoretic analysis of the glycan microheterogeneity of orosomucoid in cancer and inflamation. Electrophoresis 1986; 7: 180-6.

7 Mackiewicz A, Marcinkowska-Pięta R, Ballou S, Mackiewicz S, Kushner I. Microheterogeneity of alpha-1-acid glycoprotein in the detection of intercurrent infection in systemic protein in the detection of intercurrent infection in systemic
lupus erythematosus. Arthritis Rheum 1987; 30: 513-8.

8 Mackiewicz A, Pawlowski T, Mackiewicz-Pawlowska A, Wiktorwicz K, Mackiewicz S. Microheterogeneity forms of alpha-1-acid gycoprotein as indicators of rheumatoid arthritis activity. Clin Chim Acta 1987; 163: 185-90.

9 Pawlowski T, Mackiewicz S, Mackiewicz A. Microheterogeneity of alpha-1-acid glycoprotein in the detection of intercurrent infection in rheumatoid arthritis. Arthritis Rheum 1989; 32: 347-51.

10 Brebborowicz J, Mackiewicz A. Affinity electrophoresis for diagnosis of cancer and inflammatory conditions. Electrophoresis 1989; 10: 568-73.

11 Bierhuizen M, De Wit M, Govers C, et al. Glycosylation of three molecular forms of human al-acid glycoprotein having different interactions with concanavalin A. Eur 7 Biochem 1988; 175: 387-94.

12 Mackiewicz A, Ganapathi M K, Schultz D, Kushner I. Monokines regulate glycosylation of acute phase proteins. f Exp Med 1987; 166: 253-8.

13 Mackiewicz A, Schultz D, Mathison J, Ganapathi M K, Kushner I. Effect of cytokines on glycosylation of acute phase proteins in human hepatomama cell lines. Clin Exp Immunol 1989; 75: 70-5.

14 Mackiewicz A, Kushner I. Affinity electrophoresis for studies of mechanisms regulating glycosylation of plasma studies of mechanisms regulating glycosy
proteins. Electrophoresis 1989; 10: 830-5.

15 Mackiewicz A, Kushner I. Interferon $\beta 2 / B S F / I L-6$ affects glycosylation of acute phase proteins in human hepatoma cell lines. Scand $\mathcal{F}$ Immunol 1989; 29: 257-64.

16 Mackiewicz A, Ganapathi M K, Schultz D, et al. Transforming growth factor $\beta 1$ regulates production of acute phase proteins. Proc Natl Acad Sci USA 1990; 87: 1491-5.

17 Ganapathi M K, Schultz D, Mackiewicz A, et al. Hetero- 
geneous nature of the acute phase response: differential regulation of human serum amyloid A, C-reactive protein and other acute phase proteins by cytokines in Hep $3 B$ and other acute phase proteins by
cells. $\mathcal{F}$ Immunol 1988; 141: 564-9.

18 Fey G H, Fuller G M. Regulation of acute phase gene expression by inflammatory mediators. Mol Biol Med 1987; 4: 323-8.

19 Gauldie J, Richards C, Harnish D, Landsorp P, Baumann H. Interferon $\beta 2 / B$-cell stimulatory factor type 2 shares identity with monocyte-derived hepatocyte stimulating identity with monocyte-derived hepatocyte stimulating factor and regulates the acute phase response
Proc Natl Acad Sci USA 1987; 84: 7251-55.

20 Ropes M W, Bennett G A, Cobb S, Jacox R, Jessar S A. 1958 revision of diagnostic criteria for rheumatoid arthritis. Bull Rheum Dis 1958; 9: 175-6.

21 Tan E M, Cohen A S, Fries J F, et al. The 1982 revised criteria for the classification of systemic lupus erythematosus. Arthritis Rheum 1982; 25: 1271-7.

22 Rothfield N F, Pace N. Relation of positive LE-cell preparations to activity of lupus erythematosus and corticosteroid therapy. N Engl f Med 1962; 266: 535-8.

23 Mallya R K, Mace B E W. The assessment of disease activity in rheumatoid arthritis using multivariate analysis. Rheumatol Rehabil 1981; 20: 14-20.

24 Niedbala W, Tabaczewski P, Wiktorowicz K. The binding of SRBC by human peripheral blood monocytes. Immunol of SRBC by human

25 Laurell C B. Electroimmunoassay. Scand f Clin Lab Invest Suppl 1972; 124: 21-31.

26 Mackiewicz A, Mackiewicz S. Determination of lectin-sugar dissociation constants by agarose affinity electrophoresis. Anal Biochem 1986; 156: 481-8.

27 Dinarello C A. Interleukin-1. Rev Infect Dis 1984; 6: 51-61.
28 Pepys M B, Lauham J G, De Beer F C. C-reactive protein in SLE. Clin Rheum Dis 1982; 8: 91-103.

29 Wahl S M, McCartney-Francis N, Mergenhagen S E. Inflammatory and immunodulatory roles of TGF- $\beta$. Immunol Today 1989; 10: 258-61.

30 Walther Z, May L T, Sehgal P B. Transcriptional regulation of the interferon $\beta 2 / \mathrm{B}$ cell differentiation factor BSF-2/ hepatocyte-stimulating factor gene in human fibroblasts by other cytokines. F Immunol 1988; 140: 974-7.

31 Houssiau F A, Devogelaer J P, Van Damme J, Nagant de Deuxchaisnes $\mathrm{Ch}$, Van Snick J. Interleukin-6 in synovial fluid and serum of patients with rheumatoid arthritis and fluid and serum of patients with rheumatoid arthritis and
other inflammatory arthritides. Arthritis Rheum 1988; 31: 784-8.

32 Fong Y, Moldawer L L, Marano M, et al. Endotoxemia elicits increased circulating $\beta 2$-interferon-interleukin-6 in man. I Immunol 1989; 142: 2321-4.

33 Linker-Israeli M Bakke A C, Kitridou R C, Gendler S, Gillis S, Horowitz D A. Defective production of interleukin 1 and interleukin 2 in patients with systemic lupus erythematosus (SLE). $\mathcal{F}$ Immunol 1983; 130: 2651-6.

34 Philips R, Lomnitzer R, Wadee A A, Robson A R. Defective monocyte function in patients with systemic lupus ery-
thematosus. Clin Immunol Immunopathol 1985; 34: 69-75.

35 Shore A, Jagal S, Keystone E C. Enhanced interleukin 1 generation by monocytes in vitro is temporally linked to an early event in the onset or exacerbation of rheumatoid arthritis. Clin Exp Immunol 1986; 65: 293-302.

36 Franchimont $P$, Reuter A, Vrindts-Gevaert $Y$, et al. Production of tumour necrosis factor- $\alpha$, interferon- $\gamma$ and interleukin-2 by peripheral blood mononuclear cells of subjects suffering from rheumatoid arthritis. Scand $\mathcal{F}$ Rheumatol 1988; 17: 203-12. 